\title{
BANCADA MOTOR DE COMBUSTÃO INTERNA
}

Vicente S.P. de Queiroz ${ }^{1)}$ (engmecqueiroz92@gmail.com), Bruno de Paula Rosa ${ }^{(2)}$ (e-mail)

(1) Universidade Católica Dom Bosco (UCDB)

RESUMO: Motores de Combustão Interna (MCI) fazem parte de uma gama de equipamentos mecânicos, ao qual muitos deles se tornam imprescindíveis ao uso humano, como carros, caminhões, etc. O estudo sobre $\mathrm{MCl}$ é de grande relevância, ao passo que é necessário o entendimento básico para operá-los de maneira correta e eficaz. O presente trabalho busca, ter a finalidade de atender aos cursos voltados a área, como Engenharia Mecânica e Controle e Automação, e com isso necessitou-se conhecimento prévio sobre o assunto, para a fabricação da bancada que utiliza um $\mathrm{MCl}$ e um motor elétrico. O MCl e caixa de câmbio foram seccionados para mostrar os componentes que o formam, facilitando a visualização dos mesmos. Com auxílio do motorredutor, esses componentes são colocados em movimento, de modo que expõe a verdadeira funcionalidade da bancada, ajudando na assimilação de conteúdos relativos a ela.

PALAVRAS-CHAVE: Motor de Combustão Interna; Motor Elétrico; Bancada; Ensino; Engenharia.

\section{INTERNAL COMBUSTION ENGINE BENCH}

ABSTRACT: Internal Combustion Engines (MCl) are part of a range of mechanical equipment, many of which become essential for human use, such as cars, trucks, etc. The study on ICM is of great relevance, while basic understanding is required to operate them correctly and effectively. The present work aims to attend the courses focused on the area, such as Mechanical Engineering and Control and Automation, and with this, prior knowledge on the subject was required for the manufacture of the workbench using an $\mathrm{MCl}$ and an electric motor. The $\mathrm{MCl}$ and gearbox have been sectioned to show the components that make it easy to see. With the help of the gearmotor, these components are set in motion, so that it exposes the true functionality of the bench, helping in the assimilation of contents related to it

KEYWORDS: Internal combustion engine; Electric motor; Stand; Teaching; Engineering 


\section{INTRODUÇÃO}

Motores de combustão são basicamente máquinas térmicas que permitem transformar calor em trabalho, isto é, convertendo energia térmica em energia mecânica. O calor é gerado através da queima do combustível (possível ser obtido por várias Fontes, como por exemplo a gasolina ou o diesel), ocasionando o trabalho necessário para a movimentação dos órgãos mecânicos do motor (BRUNETTI et all, 2012). A força para tirar o motor da inércia é obtida pela realização de uma sequência de vários processos no qual está envolvido o fluido ativo (FA), que nada mais é do que o combustível que fornece energia ao sistema. Neste campo, o motor de combustão é usado em automóveis, motos, caminhões, locomotivas, navios, aviões, além de ter utilizações noutros campos tais como bombear água, produzir ar comprimido, mover máquinas (MARTINS, 2004).

Devido a combustão do FA, a força realizada é enviada para os órgãos mecânicos (como do pistão para biela, biela para a árvore de manivelas e assim por diante), onde eles são os responsáveis pela movimentação do veículo automotor. Os elementos de transmissão são utilizados para transformar e repassar posteriormente a energia mecânica oriunda do motor para as rodas do veículo de forma adequada (CHOLLET, H.M. 2002).

Para melhor entendimento sobre o funcionamento dos motores de combustão e dos componentes que o formam, o uso de bancadas se tornou vantajoso para o ensino, pois além de facilitar no aprendizado de acadêmicos, também os estimula a aprender. Pelo motor ser uma máquina térmica que envolve muita física, termodinâmica, acaba tendo uma teoria muito complexa, e não descartável, assim o estudante acaba sendo obrigado a entender, então conforme disse Araújo (2016, p. 7), o uso de experimentos científico pelo estudante aumenta o seu interesse pelo conteúdo, ou seja, aumenta a curiosidade do mesmo em sua área de estudo permitindo, muitas vezes, que certos conceitos de física sejam absorvidos naturalmente, sem que precise, inicialmente, fazer o uso de equações. 


\section{MATERIAIS E MÉTODOS}

\subsection{Materiais}

Para a realização dos cortes na tampa do cabeçote, cabeçote, bloco e cárter, as ferramentas necessárias são:

- Arco de Serra;

- Fresadora;

- Esmerilhadora (Lixadeira);

- Disco de desbaste e de corte;

- Lima Chata Murça.

- Furadeira

\subsection{Métodos}

\subsubsection{Desmontagem do $\mathrm{MCl}$}

Para fabricação da bancada, necessitou-se fazer a desmontagem do motor, retirandose os componentes agregados externamente a ele, como correia, alternador, filtro de óleo, coletor de admissão e coletor de escape, conforme a Figura 14

Figura 14 - Componentes Externos

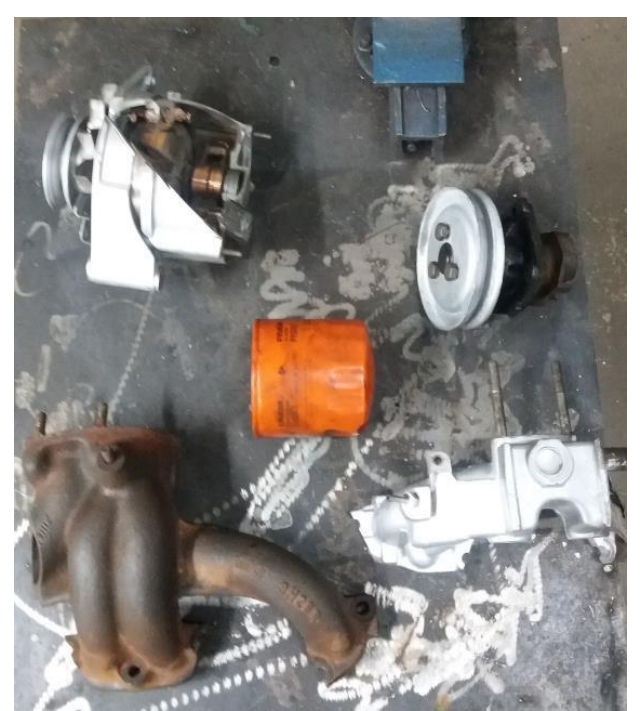

Fonte: Elaborado pelo autor, 2018. 
Depois de retirado os componentes externos, a desmontagem continuou na seguinte ordem, onde a primeira parte a ser retirada será a tampa do cabeçote (que protege o comando de válvulas e os tuchos que regulam a entrada e saída de substâncias dos cilindros do motor). O comando de válvulas será a segunda parte a ser tirada, consequentemente os tuchos serão retirados logo em seguida, terminado assim a parte do cabeçote (Figura 15).

Figura 15 - Cabeçote desmontado com seus componentes

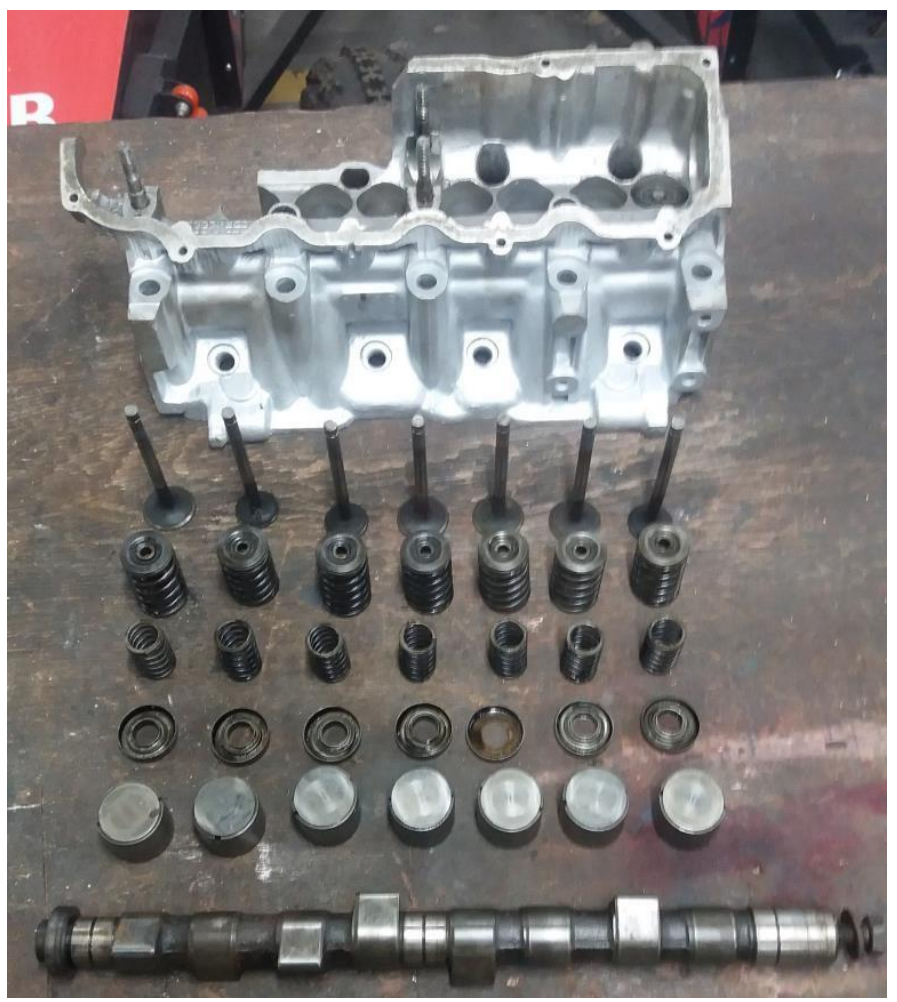

Fonte: Elaborado pelo Autor, 2018

No bloco (Figura 16a), encontra-se os pistões, o virabrequim, o pescador e o cárter. Retira-se primeiro o cárter, que nada mais é que o recipiente onde o óleo é armazenado para posteriormente lubrificar e arrefecer o motor como um todo. O pescador, responsável por captar o óleo para outros componentes móveis, será tirado sucessivamente. Os pistões (Figura 16b) são anexados ao virabrequim com os mancais de biela, então remove-se os mancais de biela e os pistões sairão. O virabrequim é retirado logo após todo esse processo. 
Figura 16a e 16b - Bloco, virabrequim e pistões
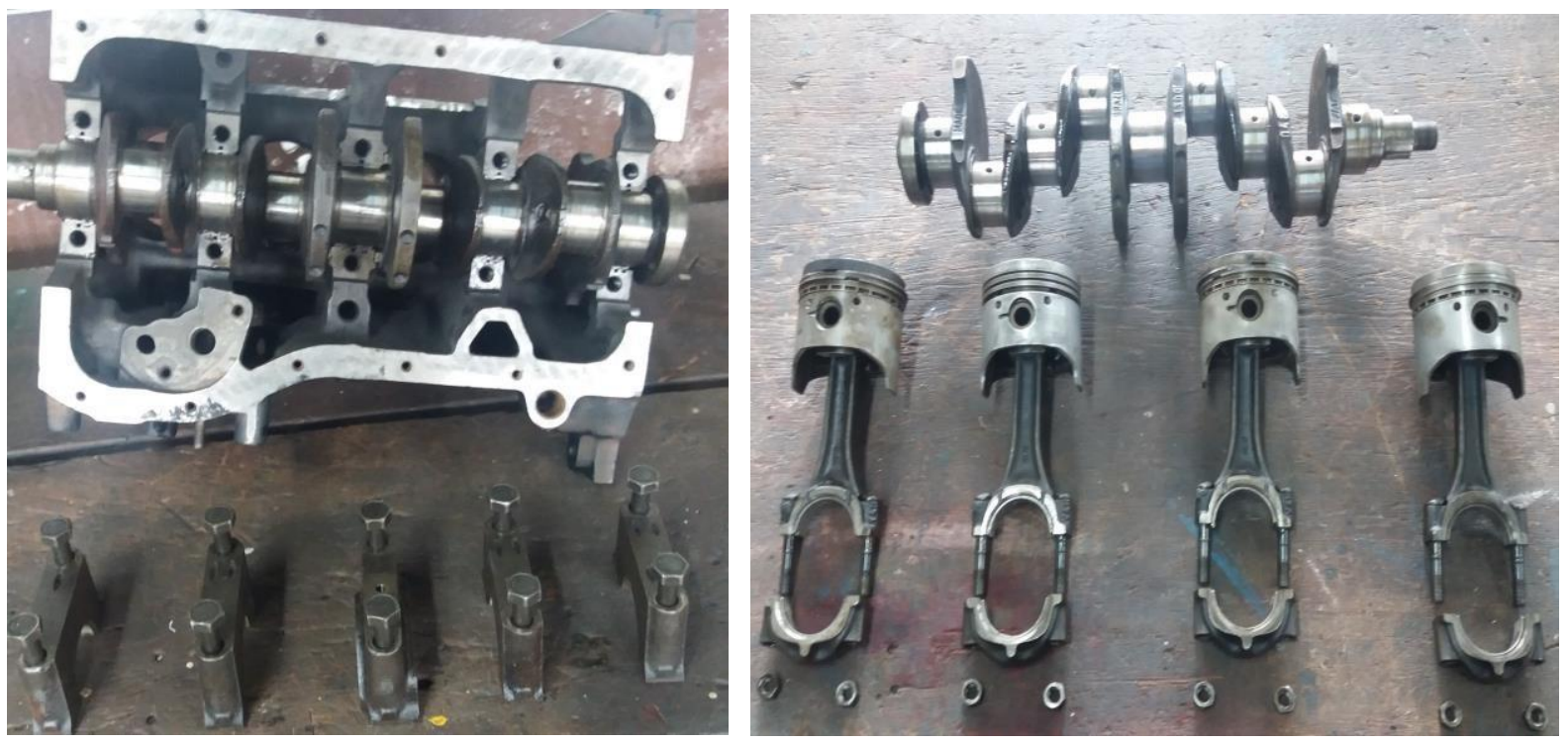

Fonte: Elaborado pelo Autor, 2018

\subsubsection{Processo de fabricação}

Depois da retirada dos componentes externos e das partes principais (tampa do cabeçote, cabeçote, bloco e cárter) foi necessário antes do corte, analisar quais partes de cada item seriam removidas (Figuras 17a e 17b).

Figura 17a e 17b - Os dois lados do bloco antes do corte
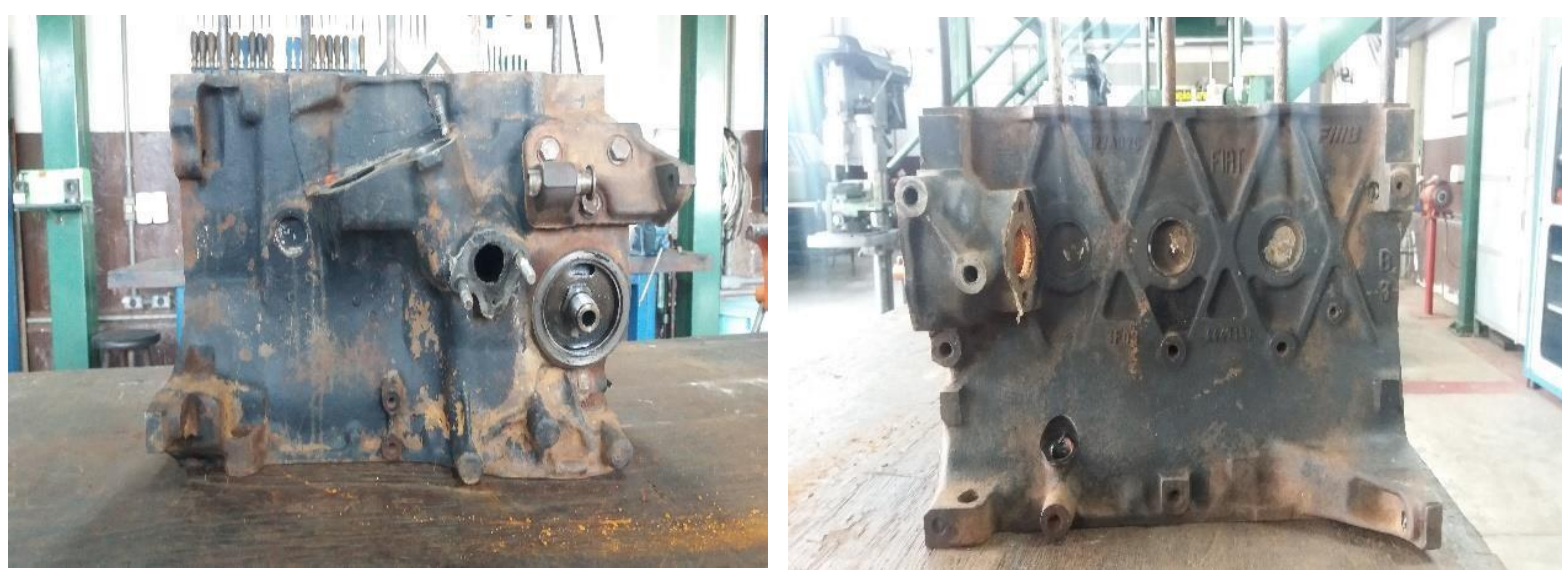

Fonte: Elaborado pelo autor, 2018

O bloco (Figura 17c e 17d), teve sua lateral esquerda riscada com giz, o que facilitou no processo de corte, onde as demarcações representam os pedaços que foram retirados com auxílio da esmerihadeira e martelo. Nessa lateral, as partes removidas são as que dão acesso ao $4^{\circ}$ cilindro, o alojamento da bomba d'água e ao virabrequim. 
Figura 17c e 17d- Bloco demarcado com giz e cortado
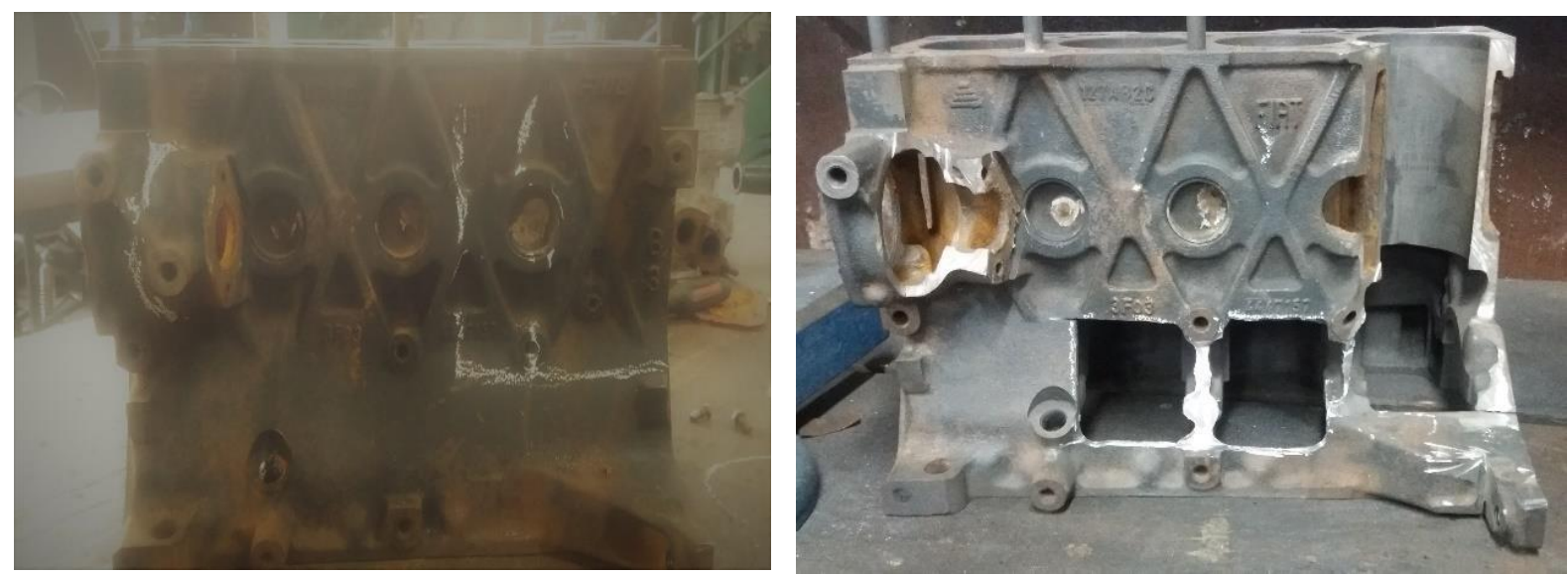

Fonte: Elaborado pelo autor, 2018

O lado direito do bloco também foi marcado com giz e posteriormente retirada a parte demarcada (Figura 14e e 14f), com auxílio da esmerilhadeira, furadeira e do martelo. A furadeira foi utilizada para fragilizar pedaços que não eram alcançados pelo disco de corte, o martelo foi para separar as partes fragilizadas do resto do bloco. Com isso, foi possível acessar o local onde o eixo atua no funcionamento da bomba de combustível, da bomba de óleo e do distribuidor (responsável pela ignição que queima a mistura ar/combustível).

Figura 17e e $17 f$ - Lado direito do bloco com o corte realizado
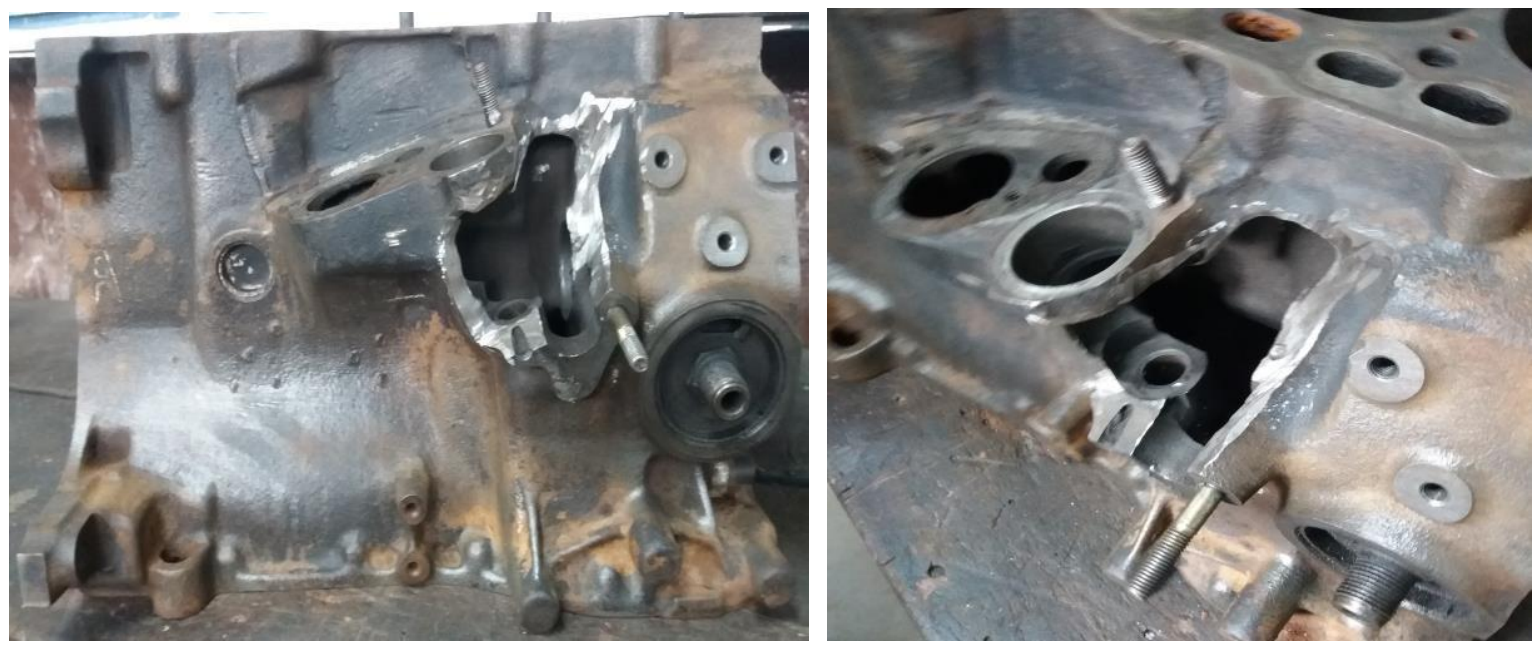

Fonte: Elaborado pelo autor, 2018

Com todas as demarcações feitas e posteriormente todas as partes retiradas, passouse lima chata murça nos cortes, para quebrar cantos vivos e dar um acabamento melhor a eles, pois o disco de desbaste também não alcançava certas partes, o que dificultava no trabalho de acabamento. Com isso a parte do bloco foi finalizada. 
O cabeçote, preso a morsa, começou a ser usinado na fresadora, e assim como o bloco, também foi demarcado na mesma posição, de forma que o corte fique alinhado em ambos (Figura 18a).

Figura 18a - Cabeçote antes da fresagem

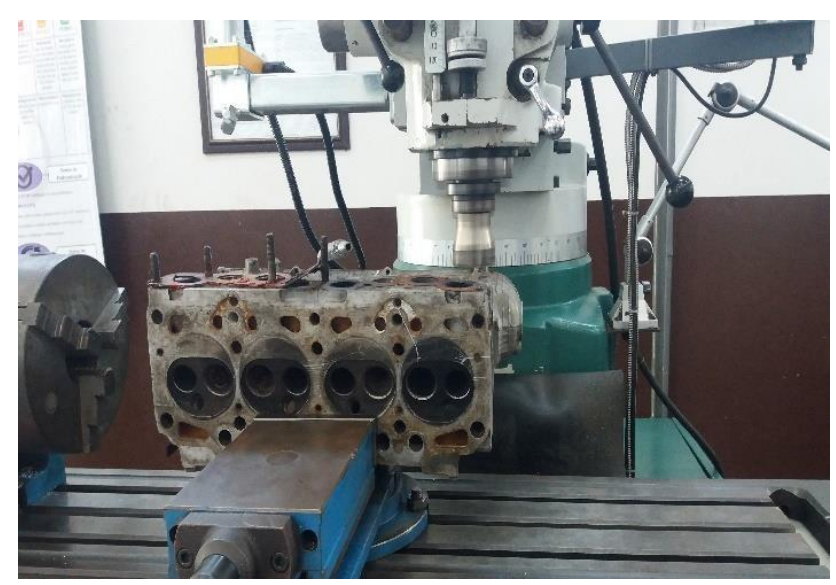

Fonte: Elaborado pelo autor,2018

Para a correta fresagem do cabeçote, antes preso na morsa da fresadora ferramenteira, necessitou-se de um suporte (Figura 18b e 18c) que prendesse de forma correta ele, pois o mesmo começou a vibrar durante o processo de usinagem (quando preso a morsa), o que poderia causar danos maiores na peça.

Figura $18 \mathrm{~b}$ e $18 \mathrm{c}$ - Vistas frontal e lateral direita do cabeçote
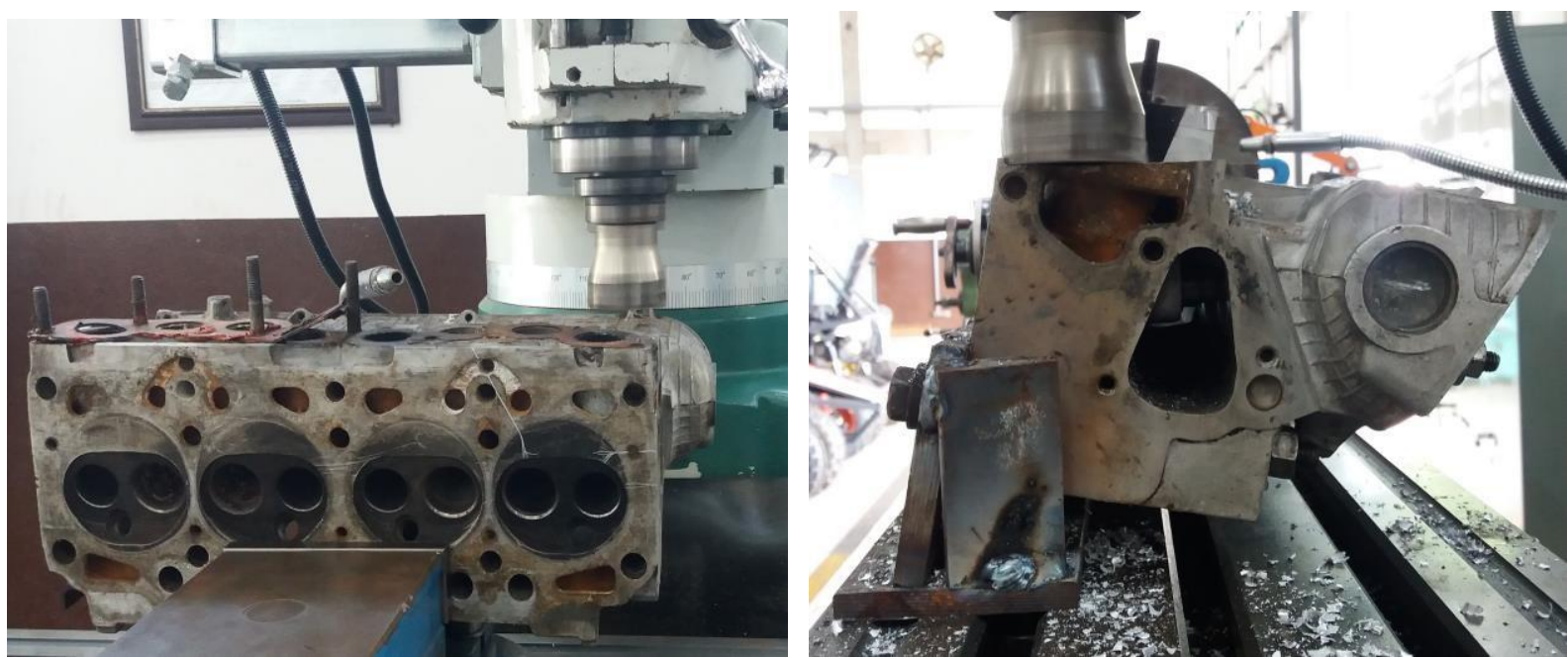

Fonte: Elaborado pelo autor,2018.

O suporte (Figura 19) foi construído com pedaços de chapa de $10 \mathrm{~mm}$ de espessura e $250 \mathrm{~mm}$ de largura, os dois pedaços soldados entre si, para garantir ainda mais a firmeza na mesa onde ele estava apoiado. Os furos presentes permitiram que o cabeçote fosse preso a esse suporte com parafusos, diminuindo as vibrações antes mencionadas. 
Figura 19a-Suporte para usinagem do cabeçote

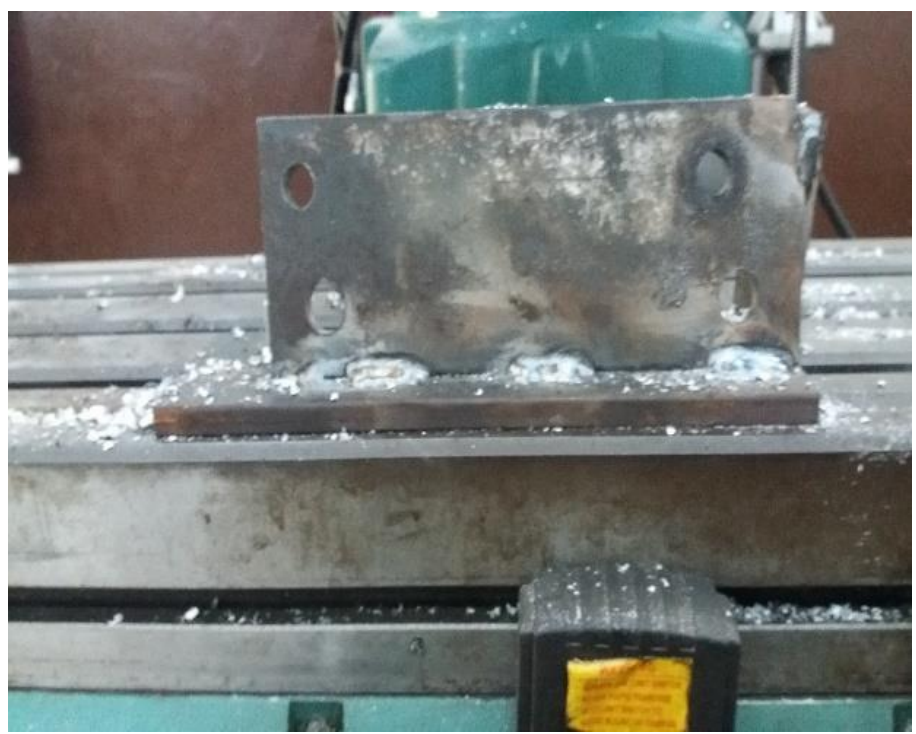

Fonte: Elaborado pelo autor, 2018.

O suporte também auxiliou na fresagem do guia de válvulas, onde o guia (parte circulada em vermelho) é inclinado em relação a superfície inferior do cabeçote, como por exemplo, apresentado nas figuras 19b e 19c.

Figura 19b e 19c - Guia de válvulas

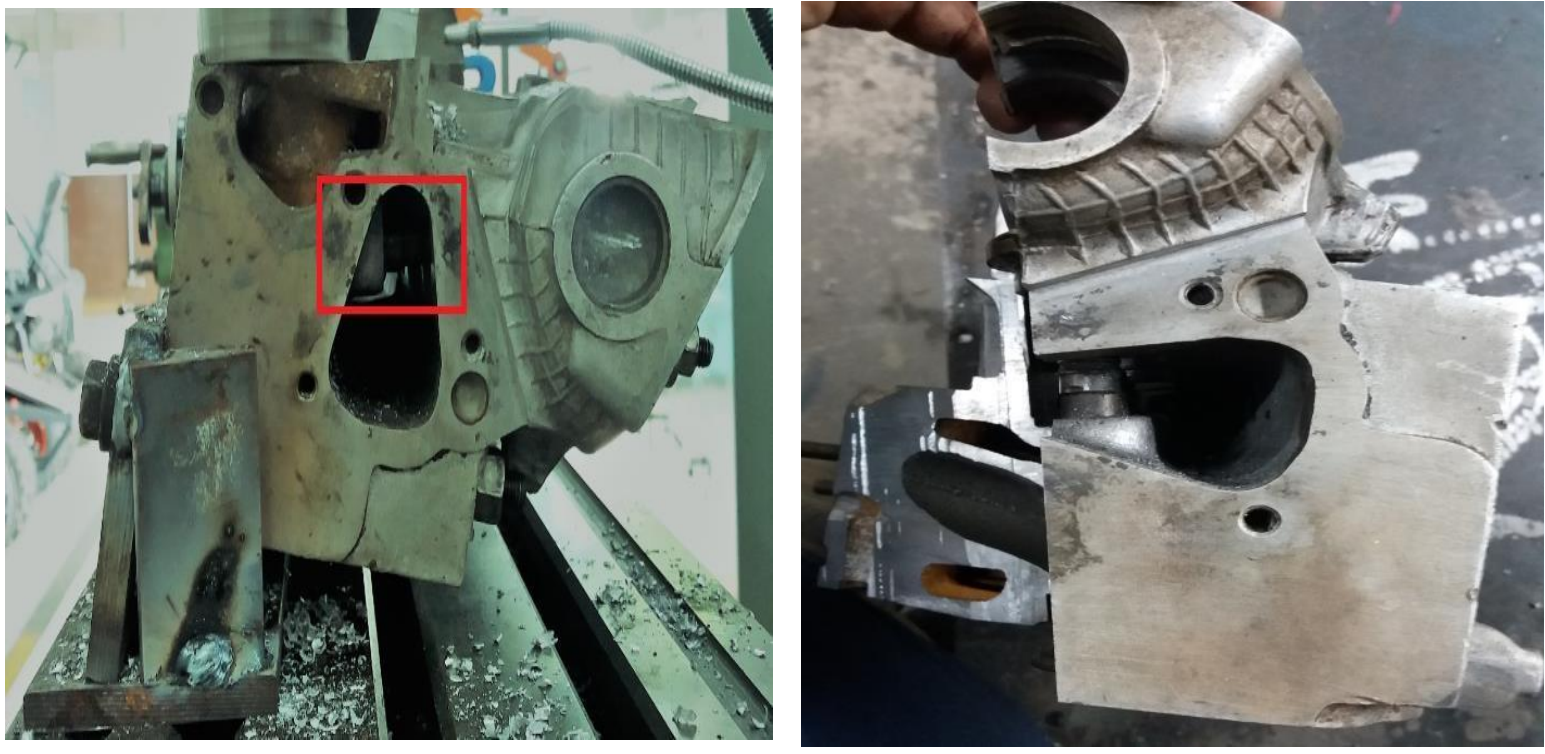

Fonte: Elaborado pelo autor, 2018

A tampa do cabeçote (Figura 20a e 20b), fabricado com material mole, como alumínio, cortou-se com auxílio da esmerilhadeira. Depois usou-se a lima para retirar as possíveis rebarbas, e deixar um bom acabamento. Ela dá acesso ao comando de válvulas e aos tuchos. 
Figura 20a e 20b - Tampa do cabeçote antes e depois do corte
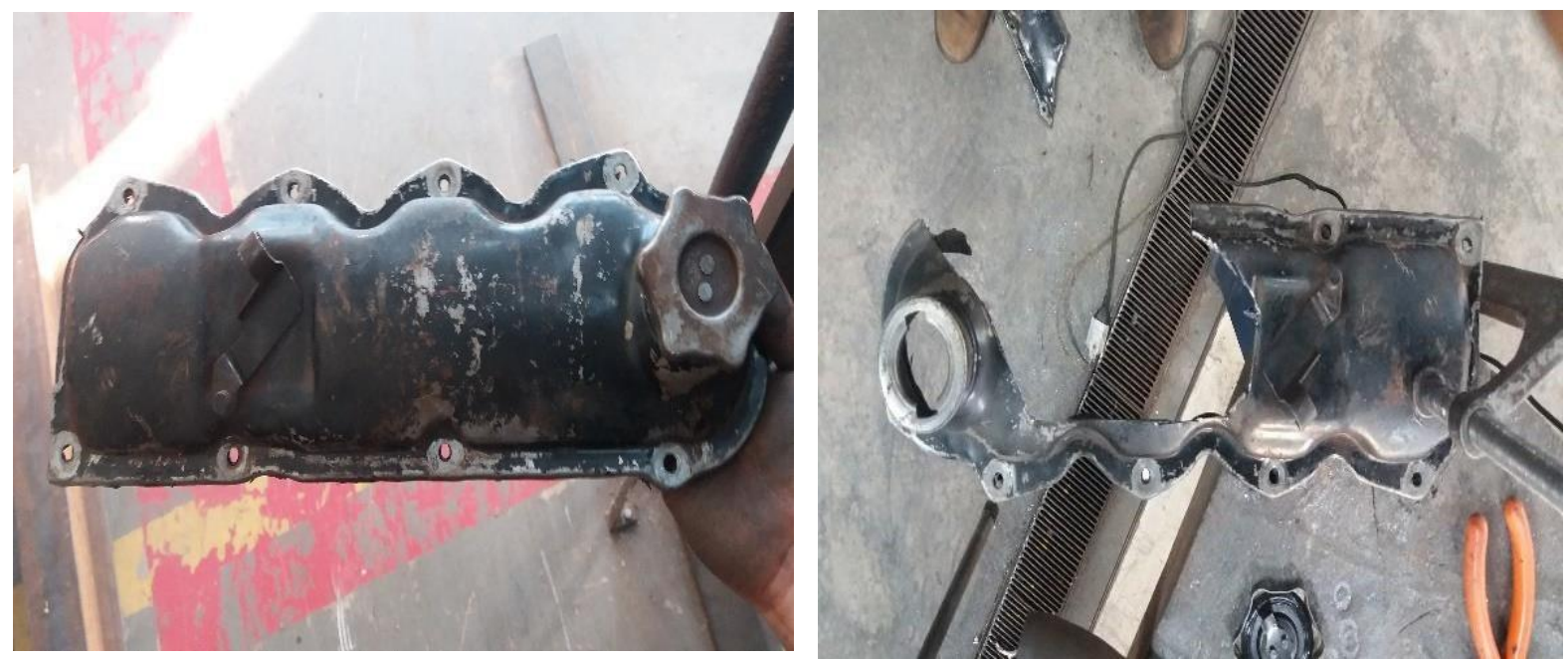

Fonte: Elaborado pelo autor

Os cortes foram realizados na lateral de todos os itens, de forma que os órgãos mecânicos do motor (como comando, pistões e virabrequim) apareçam, e assim deixe explicito a funcionalidade da bancada (Figura 21).

Figura 21 - Motor cortado

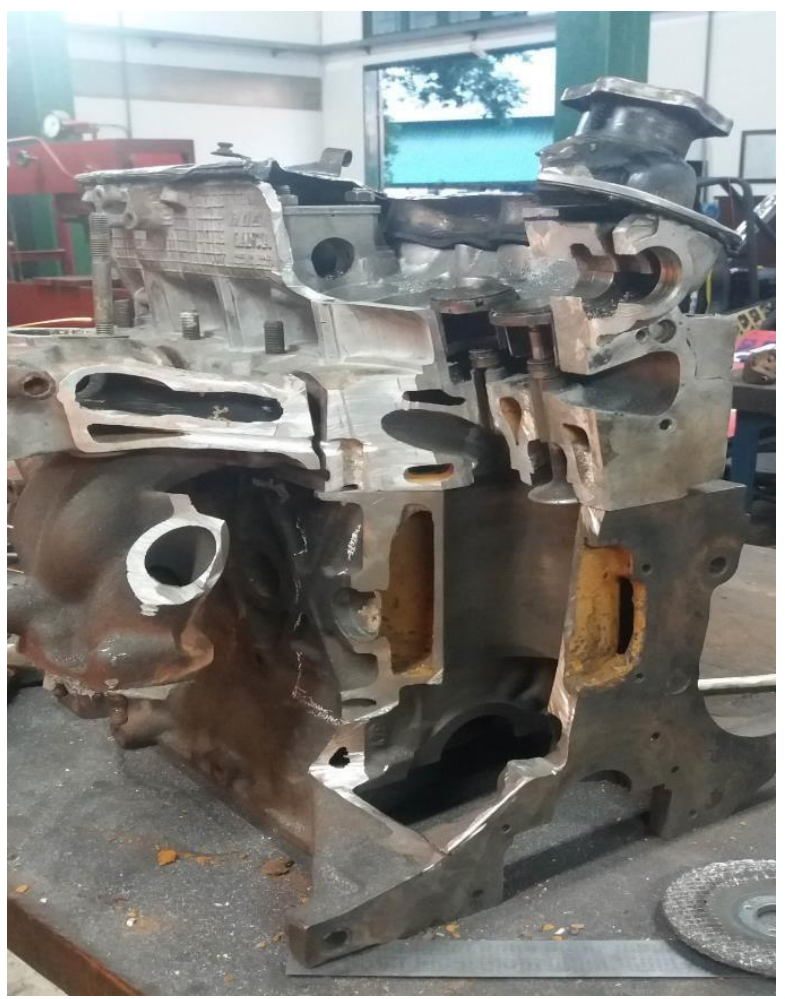

Fonte: Elaborado pelo autor, 2018 
A caixa de câmbio (Figura 22a), assim como o motor, precisou-se analisar quais partes seriam as melhores de se seccionar, pois a intenção é de mostrar os componentes que a compõe e de como é feita a transmissão de força do motor para ela.

Figura 22a - Caixa de transmissão antes do corte

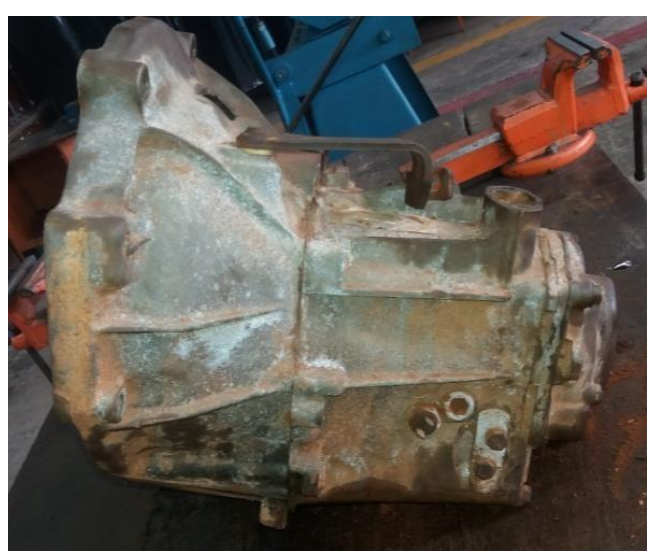

Fonte: Elaborado pelo autor, 2018

Antes do seccionamento da caixa, necessitou-se fazer sua desmontagem, retirando todos os componentes que estão dentro dela (Figura 22b).

Figura 22b - Componentes do câmbio

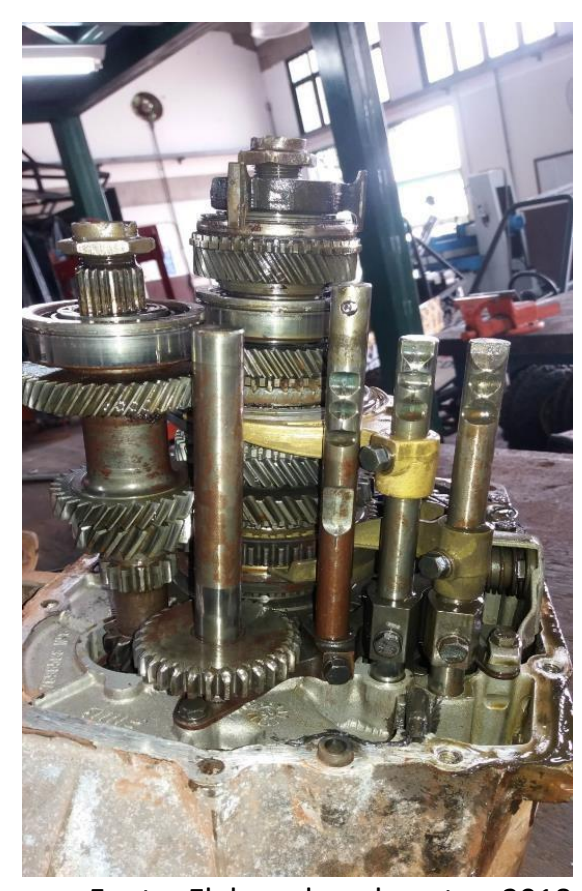

Fonte: Elaborado pelo autor, 2018. 
Depois da desmontagem, os pedaços da carcaça foram marcados com giz e dispostos lado a lado, de forma a ter uma melhor visão dos cortes que posteriormente seriam feitos nele (Figura 24).

Figura 22c - Carcaça desmontada

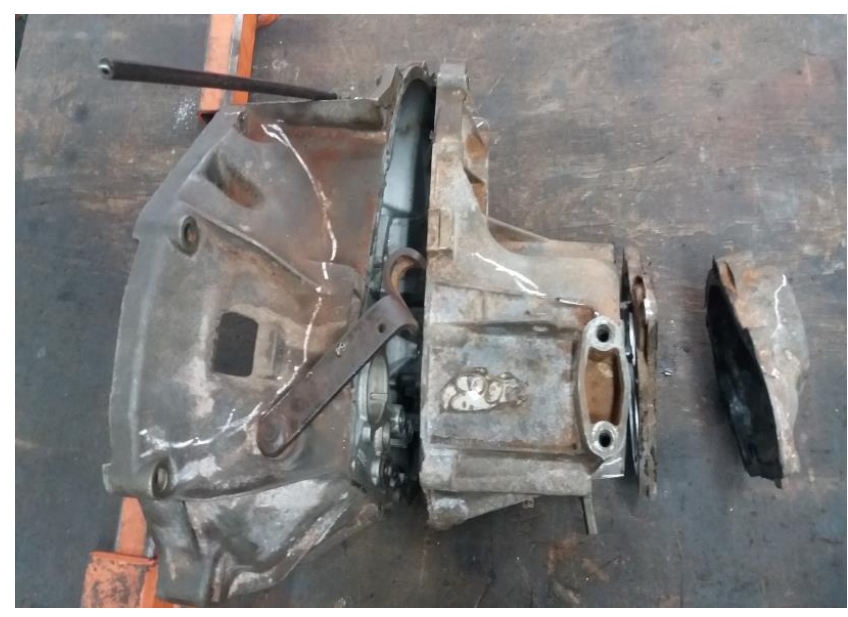

Fonte: Elaborado pelo autor,2018

Os seccionamentos foram feitos com esmerilhadeira, de modo que a maior parte dos componentes que formam a caixa fiquem expostos, deixando explicito como é seu funcionamento, como na figura $22 \mathrm{~d}$ e $22 \mathrm{e}$.

Figura 22d e 22e - Caixa de Transmissão cortada
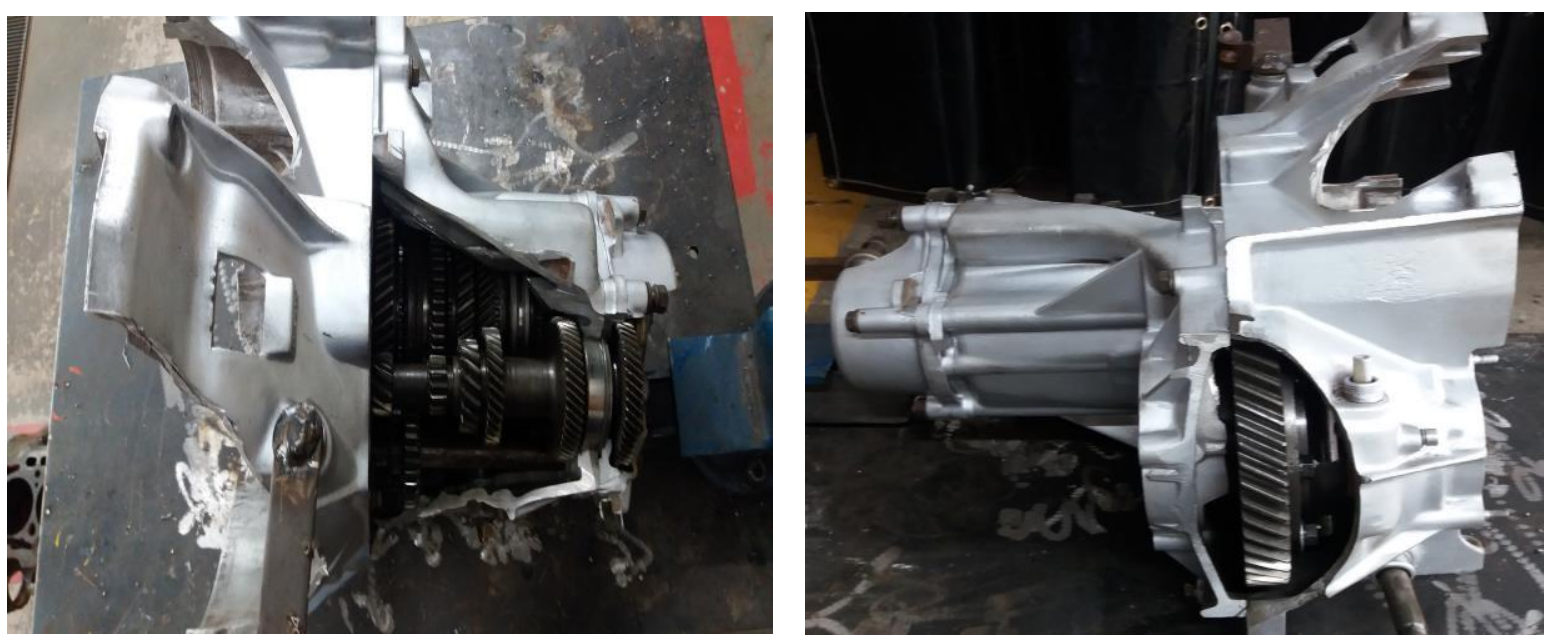

Fonte: Elaborado pelo autor, 2018

Após os seccionamentos feitos, realizou-se a montagem da carcaça com os componentes. Pintou-se com tinta spray, de forma que destacou-se os engrenamentos que formam a caixa de transmissão. 
Para a movimentação do volante de inércia, os demais itens do motor e da caixa de câmbio, um eixo foi fabricado (Figura 26), utilizando-se o pinhão do motor de arranque, um tarugo de aço de 1 pol e meia por $40 \mathrm{~mm}$ de comprimento, um pedaço de nylon de $40 \mathrm{~mm}$ de comprimento e 1 pol de espessura, e por fim um polia de $60 \mathrm{~mm}$ de diâmetro.

Figura $23-$ Eixo

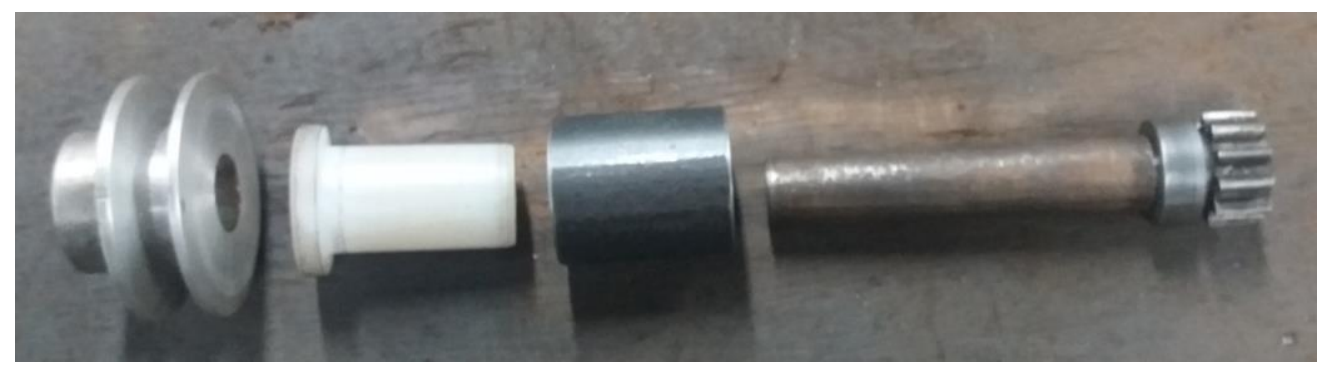

Fonte: Elaborado pelo autor,2018

Esse mecanismo auxilia na transmissão de força e movimento do motorredutor para o volante, onde a polia e o pinhão também atuam como uma redução, diminuindo ainda mais a velocidade final do volante. Soldou-se ele a uma cantoneira (Figura 27), de modo que somente as partes rotativas (como o pinhão, por exemplo) se movimentassem, permitindo o funcionamento do mesmo.

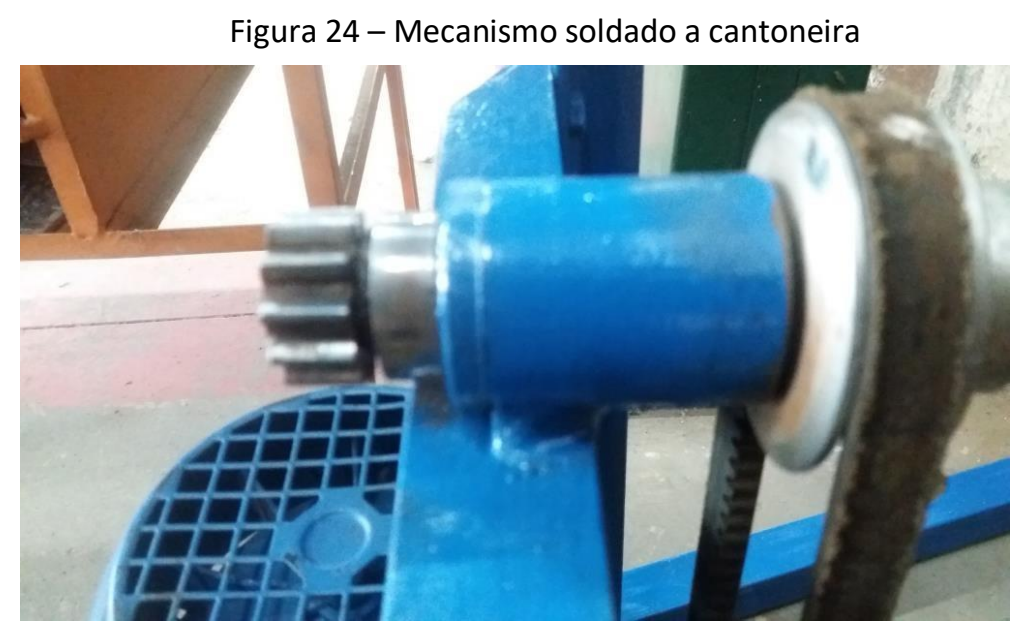

Fonte: Elaborado pelo autor, 2018 


\subsubsection{Motor Elétrico}

O motor elétrico escolhido foi um acoplado diretamente a um redutor, caracterizando como um motorredutor (Figura 28).

Figura 25 - Motor elétrico

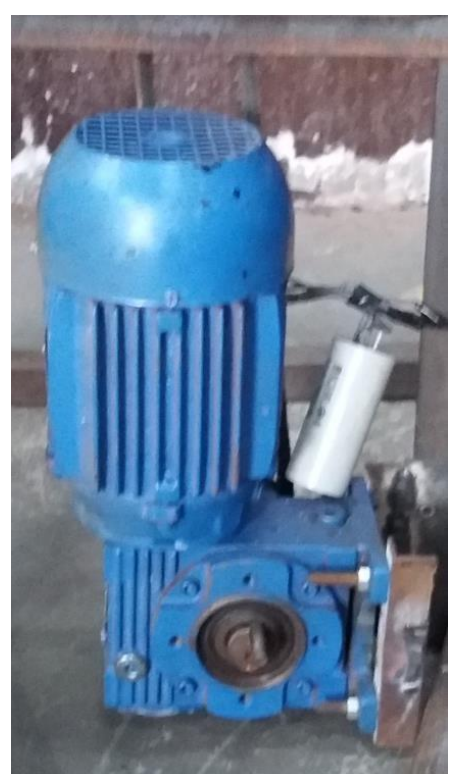

Fonte: Elaborado pelo autor, 2018.

O motorredutor utilizado possui as seguintes características, segundo tabela 1.

Tabela 1 - Características do motor redutor

\begin{tabular}{|c|c|c|c|c|c|}
\hline $\begin{array}{c}\text { Tensão } \\
(\mathrm{V}) \\
\end{array}$ & $\begin{array}{c}\text { Amperagem } \\
\text { (A) }\end{array}$ & $\begin{array}{l}\text { Frequência } \\
\qquad(\mathrm{Hz})\end{array}$ & $\begin{array}{c}\text { Rotações } \\
(\mathrm{rpm}) \\
\end{array}$ & $\begin{array}{l}\text { Potência } \\
(\mathrm{KW} / \mathrm{CV}) \\
\end{array}$ & Redução \\
\hline $127 / 220$ & $7,7 / 3,40$ & 60 & 1610 & $0,37 / 0,5$ & $1 \times 50,00$ \\
\hline
\end{tabular}

Fonte:Weg, 2016

Para conhecer as relações de transmissão que ocorrem no sistema, utiliza-se a relação de engrenagens, conforme a Eq 1.

$$
i=\frac{d 2}{d 1}=\frac{n 1}{n 2}
$$


Onde, d1 e d2 são os diâmetros do pinhão acoplado ao motor elétrico e diâmetro do volante, n1 e n2 são as rotações apresentadas no sistema.

O sistema possui duas reduções, apresentada na Figura 26, onde a polia do motorredutor está ligada com a polia do mecanismo que transmite movimento para o volante. Como a polia desse mecanismo está no mesmo eixo que o pinhão, logo a rotação será a mesma. A outra redução ocorre entre o pinhão e o volante de inércia.

Figura 26 - Reduções apresentadas no sistema

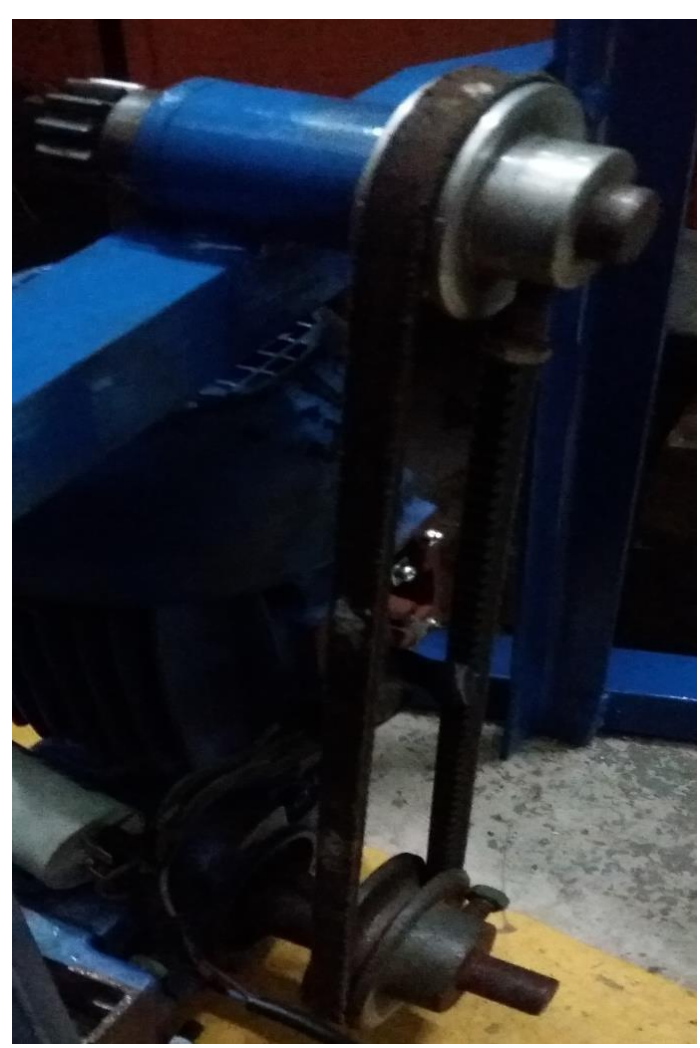

Fonte: Elaborado pelo autor, 2018 


\section{RESULTADOS E CONCLUSÕES}

Ao saber os valores dos diâmetros das polias utilizadas, do pinhão e do volante (assim como a quantidade de dentes deles), foi possível calcular o valor das relações de transmissão e saber o quanto de redução foi obtido interligando tais componentes (Tabela 1).

Tabela 2 - Diâmetros das polias, pinhão e volante

\begin{tabular}{c|c}
\multicolumn{2}{|c}{ Diâmetros (mm) } \\
\hline$\varnothing \mathrm{d} 1$ & 80 \\
$\varnothing \mathrm{d} 2$ & 60 \\
$\varnothing \mathrm{dp}$ & 30 \\
$\varnothing \mathrm{dc}$ & 245
\end{tabular}

Sabendo-se que a rotação do motor elétrico é de n=1610 rpm e que seu redutor diminui em 50 vezes a mesma, a rotação de saída encontrada foi de 32,2 rpm. A partir desse valor, foi possível encontrar as rotações da segunda polia, do pinhão e do volante. As relações de transmissão também foram achadas (Tabela 3).

Tabela 3 - Valores de rotação e de redução

\begin{tabular}{l|cc}
\multicolumn{1}{c}{$1^{\circ}$ Relação } & $2^{\circ}$ Relação \\
\hline n (rot) & 42,93 & 5,26 \\
Redução & 0,75 & 0,12
\end{tabular}

Fonte: Elaborado pelo autor, 2018.

Na $1^{\circ}$ relação de transmissão, que ocorre entre a polia do redutor e a segunda polia, ouve um aumento de $25 \%$ rotação, pois a segunda polia possui uma diferença de $20 \mathrm{~mm}$ em seu diâmetro. Com isso, a rotação foi para 42,93 rpm.

Na $2^{\circ}$ relação de transmissão, que ocorre entre pinhão e o volante, houve a redução de 8 vezes a rotação do pinhão, obtendo-se a rotação final de 5,26rpm.

Com essa baixa rotação, o conjunto funciona de maneira adequada e eficaz, facilitando assim a visualização de todos os componentes mostrados pelos cortes. 


\section{FENEMI "Como a Engenharia Mecânica e Industrial podem melhorar o Agronegócio do Brasil"}

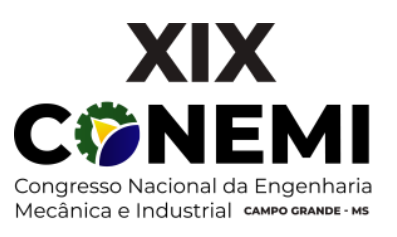

\section{CONCLUSÃO}

O estudo sobre $\mathrm{MCl}$ demonstrou-se de grande importância, pois com a finalidade de atender aos cursos voltados a área, como Engenharia Mecânica e Controle e Automação, necessitou-se conhecimento prévio sobre o assunto, para a fabricação da bancada que utilizar um $\mathrm{MCl}$ e um motor elétrico.

Conclui-se que para um motorredutor de 1610rpm com redução de 50 vezes a rotação original, foi possível reduzir ainda mais, através das relações de transmissão entre polias e engrenagens. Com isso, a rotação final encontrada foi de 5,26 rpm, atendendo de modo satisfatório a prática, pois com essa baixa rotação, facilita-se a visualização da movimentação dos componentes que formam o conjunto.

\section{REFERÊNCIAS}

ARAÚJO, E.F.D. Projetando um motor stirling como proposta para o ensino de termodinâmica.

AMENDOLA, C. H. F. Análise das estratégias de troca de marchas da transmissão automática convencional em comparação com a transmissão de dupla embreagem. 2005. 134 pg. Trabalho de conclusão de curso - Escola Politécnica de São Paulo.

PAES, A.L.; SAKAMOTO, A.Y. Projeto e construção de protótipo de motor linear para fins didáticos. 2016. 89 pg. Trabalho de conclusão de curso - Departamento de Engenharia Elétrica - Universidade Tecnológica Federal do Paraná.

BRUNETTI, F. Motores de combustão interna. São Paulo, Editora Blucher, 2012. Coleção Motores de combustão interna: Volume 1 e 2.

MARTINS, J. Motores de combustão interna. Porto; Publindustria, edições técnicas. 2004. 437p., Volume Único. $2^{\circ}$ Edição. Tendências.

CASTRO, F. D.; RAHDE, S, B. Motores Automotivos, Evolução, Manutenção e

PIMENTEL, Michele. PROJETO E CONSTRUÇÃO DE BANCADA DIDÁTICA DE MOTOR DE COMBUSTÃO INTERNA. In FEPEG 2017. Montes Claros, MG. Anais (online). Montes Claros: Unimontes, 2017. Disponível em <https://www.fepeg.unimontes.br/anais/ver/16>. Acesso em: 10 Jun 2018

http://ecatalog.weg.net/TEC_CAT/tech_motor_dat_web.asp. - Motor Weg 220V. Acesso: $25 / 03 / 2018$

BUDYNAS, RICHARD. G; KEITH NISBETT, J;Elementos de Máquinas de Shigley. Porto Alegre; Mc Graw Hill, edições técnicas. 2011. 1073pg., Volume único. $8^{\circ}$ Edição. 


\section{$\mathbf{X I X}$ \\ CIONEMI}

CHOLlET, H . M. ; Curso Prático e Profissional para Mecânicos de Automóveis, o veículo e seus componentes.Hemus, 2005. 388 pg. Volume 2, $1^{\circ}$ Edição.

http://forum.outerspace.com.br/index.php?threads/engenharia-um-pouco-sobremotores.49216. Acesso:24/09/2017

https://datamarcos.blogspot.com/2015/04/ferromarcos-como-funciona-uma.html acesso 25/06/2018

http://motoresdecarrosrdf.blogspot.com/2016/12/motor-de-combustao-interna-eexterna.html acesso 25/06/2018

https://www.carrobonito.com/2016/10/08/fim-do-motor-a-combustao-em-carros-podeestar-proximo/ acesso 25/06/2018 